\title{
PHYSICAL ACTIVITY LEVEL DOES NOT INFLUENCE THE NEUROMUSCULAR FATIGUE IN ADULTS
}

\author{
NIIVEL DE ATIVIDADE FÍSICA NÃO INFLUENCIA A FADIGA NEUROMUSCULAR EM ADULTOS
}

EL NIVEL DE LA ACTIVIDAD FISICA NO INFLUENCIA LA FATIGA NEUROMUSCULAR EN ADULTOS

Original Article

Artigo Original

Artículo Original
Frank Shiguemitsu Suzuki1,2

(Physical educator)

Marcelo Martins Kalytczak²

(Physical educator)

Cesar Augusto de Souza Casarin'

(Physical educator)

Andrey Jorge Serra ${ }^{2}$

(Physical educator)

Alexandre Lopes Evangelista ${ }^{1}$

(Physical educator)

Paulo Henrique Marchetti ${ }^{3}$

(Physical educator)

Fabiano Politti² (Physiotherapy)

Angelica Castilho Alonso'

(Physiotherapy)

Aylton José Figueira Junior ${ }^{1}$

(Physical educator)

Julien Steven Baker ${ }^{4}$

(Physical educator)

Danilo Sales Bocalini

(Physical educator)

1. Translational Physiology Laboratory. Post Graduate Program in Physical

Education and Aging Science of São Judas Tadeu University (USJT),

São Paulo, Brazil.

2. Post Graduate Program in

Biophotonic Applied in Healthy

Sciences and Rehabilitation Science

of Nove de Julho University

(UNINOVE), São Paulo, Brazil.

3. Post Graduate Program in Science

of Human Movement, College of

Health Science, Methodist

University of Piracicaba (FACIS),

Piracicaba, Brazil.

4. University of the West of Scotland, Institute of Clinical Exercise and Health Science, Hamilton,

Lanarkshire, Scotland.

\section{Correspondence:}

Danilo Sales Bocalini

Programa de Pós-Graduação em

Educação Física e Ciências do

Envelhecimento, Universidade

São Judas Tadeu.

Rua Ary Barroso, 68, apto 105, Torre 1.

Ferrazópolis, São Bernardo do

Campo, São Paulo, Brazil. 09790-240.

bocaliniht@hotmail.com

\begin{abstract}
Introduction: Fatigue during voluntary muscle contractions is a complex and multifactorial phenomenon associated with central changes and adaptations of the neuromuscular system. Objective: The purpose of this study was to evaluate the fatigue induced by intermittent successive extension of the knee between active and inactive university students. Method: Twenty healthy men ( $\geq 18$ years), voluntarily participated in this study. To determine the maximum voluntary isometric contraction (MVIC) of the knee extensors muscle group, three sets of isometric contractions of knee extension were performed for five seconds with five minutes of rest between sets. The fatigue protocol consisted of 10 sets of 10 maximal concentric contractions of the extensor on the right knee, performed at $75 \%$ of MVIC with an interval of 45 ". Results: Significant reductions were observed $(p<0.01)$, both in isometric strength $(-34 \pm 4 \%)$ and the dynamic strength $(-40$ $\pm 3 \%$ ). In addition, the slope of relationship strength $x$ repetition was $-0.79 \pm 0.07 \mathrm{Nm} /$ repetitions and the magnitude of the effect reached -8.90 . Conclusion: The protocol was useful to induce peripheral fatigue, although muscle strength is greater in the active group. In both isometric and dynamic action, muscle fatigue did not differ between groups.
\end{abstract}

Keywords: muscle strength; dynamometer; knee; isometric contraction.

\section{RESUMO}

Introdução: A fadiga durante contrações musculares voluntárias é um fenômeno complexo e multifatorial, associado a alterações centrais e adaptações do sistema neuromuscular. Objetivo: Avaliar a fadiga induzida por sucessivas extensões intermitentes do joelho entre estudantes universitários ativos e inativos. Métodos: Vinte homens saudáveis ( $\geq 18$ anos) participaram voluntariamente deste estudo. Para determinar a contração isométrica voluntária máxima (CIVM) do grupo muscular extensores do joelho, foi utilizado o valore médio de três contrações isométrias de extensão do joelho, durante cinco segundos, com cinco minutos de intervalo entre as séries. O protocolo de fadiga foi composto por 10 séries de 10 contrações concêntricas máximas sobre os extensores do joelho direito, realizadas a $75 \%$ da CIVM com intervalo de 45". Resultados: Reduções significativas $(p<0,01)$, tanto na força isométrica (-34 $\pm 4 \%$ ) quanto na dinâmica (-40 $\pm 3 \%$ ). Adicionalmente, a reta da relação força $\times$ repetição assumiu inclinação de -0,79 $\pm 0,07 \mathrm{Nm} /$ repetições e a magnitude do efeito atingiu -8,9. Conclusão: O protocolo foi útil para induzir a fadiga periférica, embora a força muscular seja maior no grupo ativo. Tanto na ação isométrica quanto dinâmica, a fadiga muscular não diferiu entre os grupos.

Descritores: dinamômetro; força muscular; joelho; contração isométrica.

\section{RESUMEN}

Introducción: La fatiga durante las contracciones musculares voluntarias es un fenómeno complejo y multifactorial, asociado a los cambios centrales y adaptaciones del sistema neuromuscular. Objetivo: Evaluar la fatiga inducida por las extensiones sucesivas intermitentes de la rodilla entre los estudiantes universitarios activos e inactivos. Métodos: Veinte hombres sanos ( $\geq 18$ años) participaron voluntariamente en este estudio. Para determinar la contracción isométrica voluntaria máxima (CIVM) del grupo de los músculos extensores de la rodilla, se realizaron tres contracciones isométricas de extensión de la rodilla, durante cinco segundos, con cinco minutos de descanso entre las series. EI CIVM se determinó por la media de los tres intentos. El protocolo de la fatiga consistió en 10 series de 10 contracciones concéntricas máximas del extensor de la rodilla derecha, realizadas en el 75\% de CIVM con un intervalo de 45". Resultados: Se observaron reducciones significativas $(p<0,01)$, tanto en la fuerza isométrica $(-34 \pm 4 \%)$ y la dinámica $(-40 \pm 3 \%)$. Además, la recta de la relación fuerza x repetición presentó inclinación de $-0,79 \pm 0,07 \mathrm{Nm} /$ repeticiones y la magnitud del efecto alcanzó -8,9. Conclusión: El protocolo fue útil para inducir fatiga periférica, aunque la fuerza muscular es mayor en el grupo activo. En acción isométrica y dinámica, la fatiga muscular no difirió entre los grupos.

Descriptores: dinamómetro; fuerza muscular; rodilla; contracción isométrica. 


\section{INTRODUCTION}

Fatigue during voluntary muscular contractions is a complex and multifactorial phenomenon associated with both central changes and adaptations in the neuromuscular system. Generally, muscle fatigue is defined as a progressive and transient reduction of maximal force production induced by repeated muscle contractions independently of task type sustained or not ${ }^{1,2}$.

Muscle fatigue activities may occur through either peripheral or central pathways, related to muscle failure in generating force at the level of the neuromuscular junction ${ }^{3}$. Central fatigue is related to a progressive reduction in voluntary activation that encompasses supraspinal and spinal circuitry ${ }^{4,5}$. Neuromuscular fatigue during sustained static or dynamic contractions is an important limiting factor in the development of performance in many occupations including sports $s^{6,7}$. There are different protocols able to promote muscular fatigue, however, Isokinetic fatigue protocols are ${ }^{8-10}$ currently considered as a gold standard in clinical and sports approaches ${ }^{11-13}$.

Schwendner et al. ${ }^{14}$ reported that no fallers have greater muscle endurance (maximal knee extensions until force output, 50\% of maximal voluntary contraction for two consecutive repetitions) than fallers (95 vs. $81 \mathrm{sec}$ ). Thus, muscle fatigability may be an important determinant of physical function, although few studies ${ }^{11,13}$ the rate-limiting precursor of carnosine, has been shown to elevate the muscle carnosine content. We aimed to investigate, using proton magnetic resonance spectroscopy (proton MRS were found that evaluated the fatigability on active and inactive subjects.

Paasuke et al. ${ }^{15}$ evaluated the neural and muscular strength changes during fatigue produced in repeated submaximal static contractions of knee extensors in endurance-trained, power-trained and untrained men. There were no changes on latency of patellar reflex after repeated exhaustive submaximal static contractions, which indicate no changes on sensory and motor nerve conduction characteristics. Differences in neuromuscular properties were observed in athletes, untrained individuals and endurance-trained athletes ${ }^{15}$. According to the authors, the differences in strength may be attributed to the larger muscle cross-sectional area and type I/II fiber area ratios in athletes compared to untrained subjects or endurance trained athletes ${ }^{16,17}$.

Currently, physical inactivity had been considered a main risk factors for the development of chronic diseases and disability ${ }^{18,19}$. From an epidemiological point of view, studies ${ }^{20}$ have shown high rates of physical inactivity worldwide. Whereas these properties are strongly influential in muscle performance, non-active individuals have lower strength development, yet little is known about the fatigue of these individuals ${ }^{11}$. Considering this, the aim of the present study was to assess the ability of a protocol used to induce knee extension fatigue by multiple sets of intermittent Isokinetic exercise in both active and inactive adult subjects.

\section{METHOD}

Twenty adult healthy men ( $\geq 18$ years), physically independent, voluntarily participated in this study (table 1). The International Physical Activity Questionnaire (IPAQ) was used to estimate physical activity levels. All participants were interviewed using the IPAQ short form. The questions were based on the preceding weeks physical activity levels, exploring the frequency and duration of physical activity including walking, moderate and vigorous physical exercise and sitting time. Individuals were considered active if they participated in physical activity for more than 150 minutes per week, and inactive if their participation levels were less than 150 minutes per week ${ }^{21}$. After IPAQ analyzes the subjects were distributed in inactive (n: 10) and active (n: 10) groups. Exclusion criteria were: positive clinical diagnosis of diabetes mellitus, smoker and musculoskeletal complications and/or cardiovascular alterations confirmed by medical evaluation. This study was approved by the University research ethics committee and all subjects read and signed an approved informed consent document (\#786.066/2014).

The experimental design is presented in Figure 1. Subjects attended in the Laboratory four times to perform the Isokinetic evaluation by using a Biodex System 3 (Biodex, Inc., Shirley, NY). The validity coefficient of this instrument is 0.99 , and the reproducibility measuring peak torque during knee extension was 0.92 at younger's subjects. Briefly, on the first day the subjects signed consent forms and completed the IPAQ. On the second day the anthropometric data (height, and weight) was evaluated. Third day the subjects were placed on the Isokinetic Dynamometer in a comfortable, upright, seated position for familiarization procedures. Straps were used to fix the thigh, pelvis, and trunk to prevent extraneous body movement. The axis of the dynamometer was aligned with the axis of right knee joint rotation. Arms were placed across the chest with hands grasping the straps. All subjects performed eight repetitions of submaximun concentric knee extension/flexion at $120^{\circ} \cdot \mathrm{s}^{-1}$. The knee joint range of motion was 90 to $10^{\circ}$ of knee flexion. The calibration of the Isokinetic Dynamometer was performed according to the specifications of the manufacturer before each test, and finally, on the fourth day the fatigue protocol was performed. All testing and experimental procedures were performed on the same time of day to exclude diurnal variation. Anthropometric measurements: Height was measured by a Cardiomed (WCS model) stadiometer, with an accuracy of $115 / 220 \mathrm{~cm}$. The measurement was performed with the cursor at an angle of $90^{\circ}$ with respect to scale, with the patient in a standing position with feet together in contact with Stadiometer. The subjects were instructed to stay in inspiratory apnea and head parallel to the ground. Total body mass was measured by a calibrated Filizola electronic scale (Personal Line Model 150) with a $100 \mathrm{~g}$ scale and a maximum capacity of 150 $\mathrm{kg}$. Body mass index $\left(\mathrm{BMl}, \mathrm{kg} / \mathrm{m}^{2}\right)$ was calculated using the equation $\mathrm{BMI}=$ weight/height ${ }^{2}$.

Fatigue protocol: The subjects performed a standardized warm-up comprising of five submaximal concentric and eccentric contractions at $120^{\circ} \mathrm{s}^{-1}$ in test position prior to data collection. Following the warm-up, subjects were asked to perform three maximal isometric voluntary contractions on the right knee extensors at $90^{\circ}$ during five seconds to determine the maximal torque before and after the fatigue protocol. $A$ rest interval of 45 seconds was prescribed between each set of muscular action, in order to minimize repetition effects especially during the post-test session. All test sessions were supervised by the same researcher. After the determination of maximal torque, all subjects performed a fatiguing protocol (concentric extension and eccentric flexion on the knee joint) comprising 10 sets of 10 maximal concentric contraction on right knee extensors at $75 \%$ of maximal isokinetic torque ${ }^{22}$. The angular velocity was $120^{\circ} \mathrm{s}^{-1}$, over range of motion of maximum flexion and extension, with 45 seconds of rest observed between sets ${ }^{22}$. During the test, all subjects were encouraged to exert maximal tension throughout the entire range of motion for all sets (Figure 1).

\section{Statistical analyses}

The D'Agostino-Pearson test was applied to Gaussian distribution analysis. The paired Student's t-test and One-way ANOVA followed by Kruskal-Wallis or Bonferroni's post-hoc test were performed to compare differences on fatigue protocol. Comparison analysis between inactive and active groups was performed by a repeated-measures ANOVA, followed by Kruskal-Wallis or Bonferroni's post-hoc test. Cohen's effect sizes (ES) were calculated, and evaluated based on the following criteria proposed 


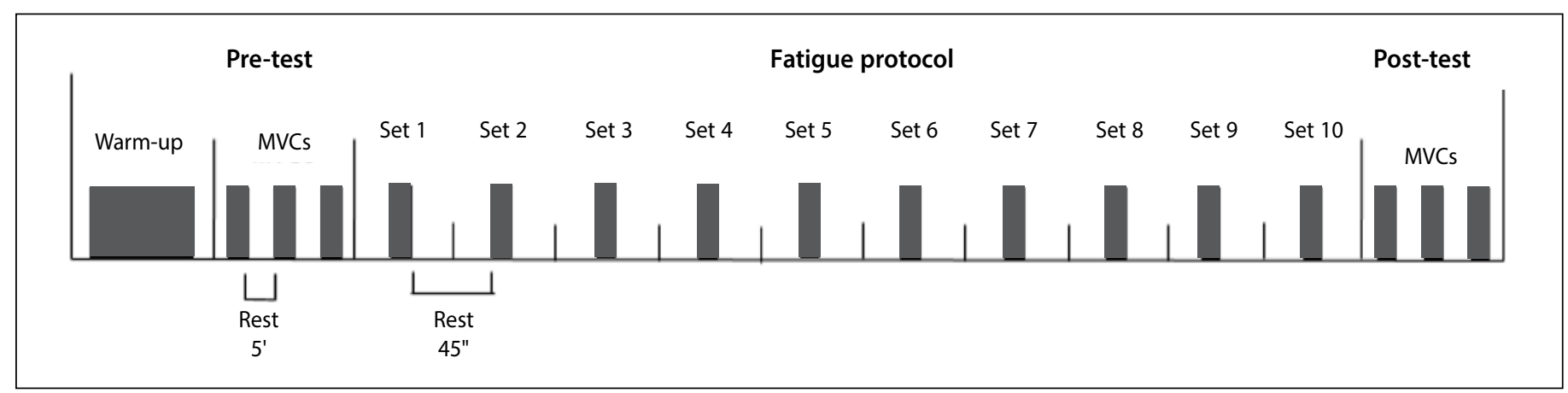

Figure 1. Experimental design of fatigue protocol. MVCs: maximum voluntary contraction.

by Rhea (2004) : $<0.50$ trivial, 0.50 to 1.25 small, 1.25 to 1.9 moderate and $>2$ large. An alpha of 0.05 was used to determine statistical significance. All data values were expressed as mean \pm standard deviation. All analyses were performed using SPSS software (v 15.0; IBM, Armonk, NY, USA).

\section{RESULTS}

The anthropometric parameters are described in table 1. There were no significant differences for age and anthropometric parameters between groups as showed in table 1.

The absolute peak torque is observed in Figure 2. No participant had or reported any discomfort during the test sessions, however, both in maximal torque (Panel A: Before: $307 \pm 12$, After: $209 \pm 13$; Nm) with fatigability at $-34 \pm 4 \%$. Additionally, a large effect size was observed in both to peak torque (-8.16).

In Figure 3 shows a decline in torque production during repetitions of fatigue protocol. The values of the linear correlation coefficients ( $r$ ) ranged value of 0.7505 . The slopes range of maximum torque was $-0.79 \pm 0.07 \mathrm{Nm} /$ repetitions.

Considering the dynamic torque peak between absolute fatigue (Figure $4 \mathrm{~A}$ ) and relative fatigue (Figure $4 \mathrm{~B}$ ) analysis, there was a significant decrease $(40 \pm 3 \%, \mathrm{p}<0.001)$ through sets in relation to first set, and a large effect size to absolute fatigue (-8.9\%).

Significant differences $(p<0.0001)$ were found between time spent

Table 1. Sample characteristics

\begin{tabular}{c|c|c|c|c}
\hline & General & Inactive & Active & Significance \\
\hline Age (years) & $27 \pm 3$ & $25 \pm 2$ & $28 \pm 2$ & $\mathrm{p}=0,3021$ \\
\hline Total body mass $(\mathrm{kg})$ & $78 \pm 3$ & $80 \pm 5$ & $77 \pm 3$ & $\mathrm{p}=0,6385$ \\
\hline Height $(\mathrm{m})$ & $1,77 \pm 0,1$ & $1,76 \pm 0,1$ & $1,77 \pm 0,2$ & $\mathrm{p}=0,8092$ \\
\hline BMI $\left(\mathrm{kg} / \mathrm{m}^{2}\right)$ & $24 \pm 1$ & $25 \pm 2$ & $24 \pm 1$ & $\mathrm{p}=0,4657$ \\
\hline TPA $(\mathrm{min})$ & $221 \pm 32$ & $85 \pm 7$ & $357 \pm 18$ & $\mathrm{p}=0,0001$ \\
\hline
\end{tabular}

values expressed as the mean \pm standard error deviation. BMl: body mass index. TPA: time spent weekly by physical activity.

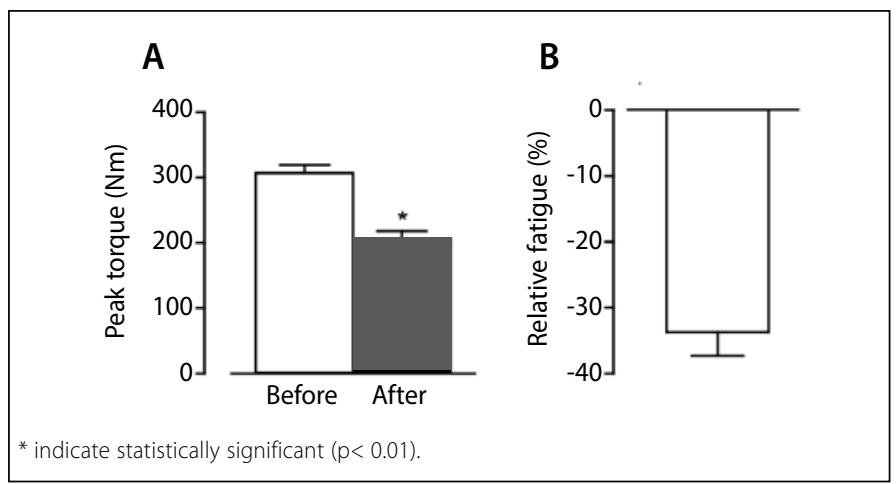

Figure 2. Values expressed as the mean \pm standard error deviation of isometric peak torque (panel A) and relative fatigue (Panel B). weekly by physical activity (table 1) between groups. The differences on inactive and active isometric peak torque can be observed in Figure 5. The maximal torque (Figure $5 \mathrm{~A}$ ) of active group was higher $(p<0.001)$ than the inactive group. After the applied muscle fatigue protocol, a significant decrease $(p<0.01)$ on torque peak in both groups (Active: before: $330 \pm 13 \mathrm{Nm}$, after: $220 \pm 13 \mathrm{Nm}$; Inactive: before: $281 \pm 17 \mathrm{Nm}$, after: $189 \pm 22 \mathrm{Nm}$ ) were found. There was no significant difference on fatigability (Figure 5B) between groups (Active: $35 \pm 6 \%$; Inactive: $33 \pm 5 \%$ ). In both groups a large effect size was observed after to torque peak (Active: 8.46; Inactive: 4.18).

Considering the fatigue protocol load, there was no significant difference between groups (Inactive: 199 \pm 12 Nm, Active: $217 \pm 10 \mathrm{Nm}$, $p=0.8765$ ). Figure 6 shows the decrease in torque production during individual repetitions of the fatigue test. The values of linear correlation coefficients( $r$ ) ranged from 0.6951 (active) to 0.7417 (inactive). When was considered the slopes of maximum torque there was no significant differences through sets between groups (inactive: $-0.84 \pm 0.24 \mathrm{Nm} /$ repetitions; and, active: $-0.73 \pm 0.19 \mathrm{Nm} /$ repetitions; $p=0.7401$ ).

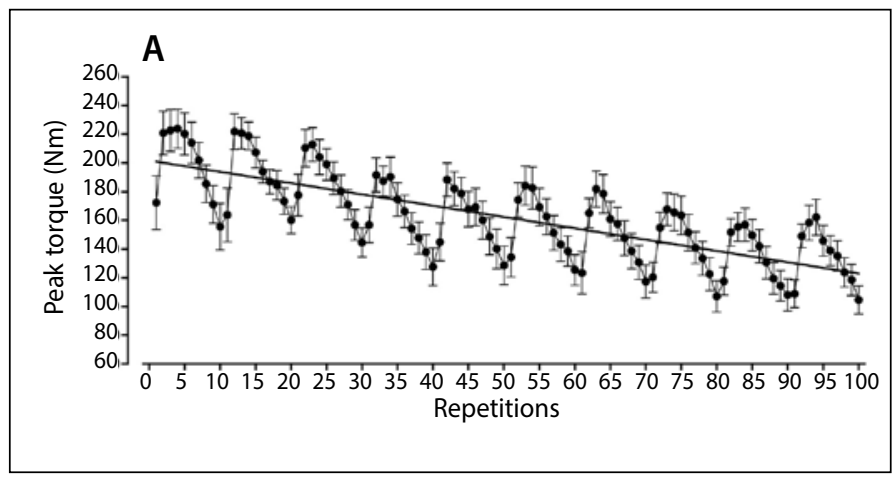

Figure 3. Values expressed as mean \pm SE. Panel A: decline in peak torque production in inactive and active after 10 sets of 10 concentric isokinetic mode knee extensions at $120^{\circ} \mathrm{sec}^{-1}$ with 45 seconds rest between sets (repetition one eliminated from analysis).

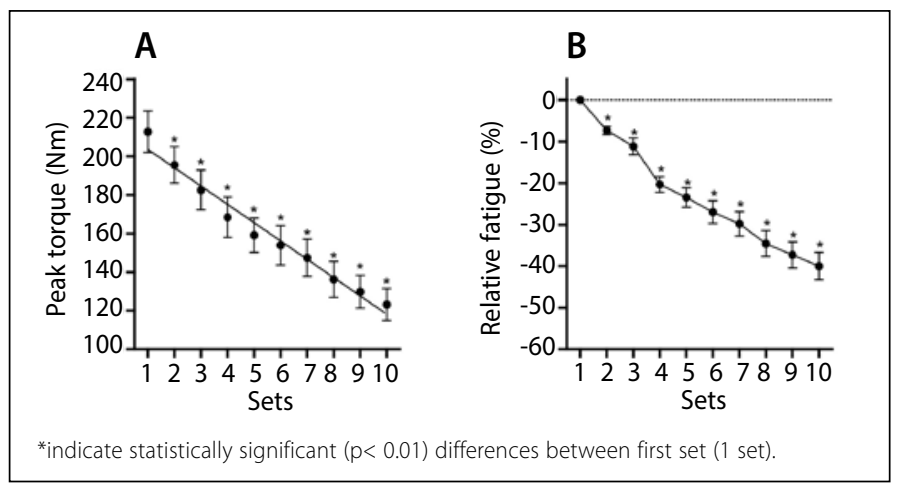

Figure 4. Decline of absolute fatigue (Panel B) and relative fatigue (Panel C) after 10 sets of 10 concentric isokinetic mode knee extensions at $120^{\circ} \mathrm{sec}^{-1}$. 
After absolute fatigue analysis (Figure 7A), there were significant $(p<0.001)$, decreases on dynamic peak torque through sets in both groups. However, there was significant differences between the groups (inactive: $106 \pm 13 \mathrm{Nmand}$ active: $143 \pm 8 \mathrm{Nm}, \mathrm{p}<0.001$ ) only at $10^{\circ}$ set between. Although, there was found high values of relative fatigue (Figure 7B) on inactive group (-46 $\pm 5 \%$ ) related to active group $(-31 \pm 4 \%)$, indicating that both groups presented same tolerance to fatigue. The analysis of the effect size to both inactive (7.23) and active (9.25) groups presented values of great influence.
A

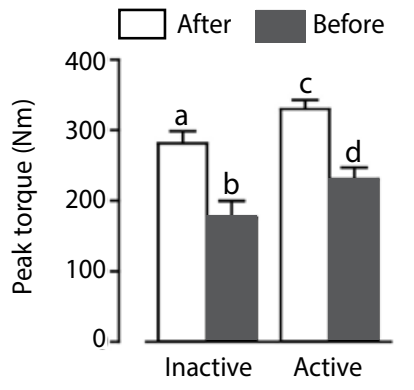

B

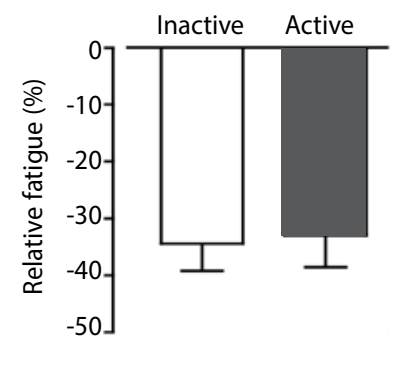

Figure 5. Values expressed as the mean \pm standard error deviation of isometric peak torque (panel A) and relative fatigue (Panel B) of inactive and active subjects. Different letters indicate statistically significant $(p<0.05)$ differences between groups.

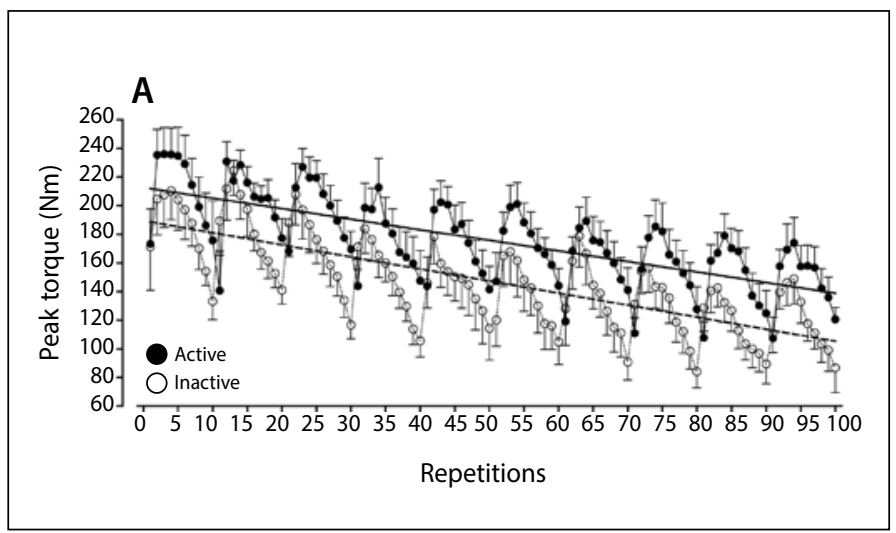

Figure 6. Values expressed as mean \pm SE. Panel A: decline in peak torque production in inactive and active after 10 sets of 10 concentric isokinetic mode knee extensions at $120^{\circ} \mathrm{sec}^{-1}$ with 45 seconds rest between sets (the first repetition was eliminated from analysis) of inactive and active subjects.

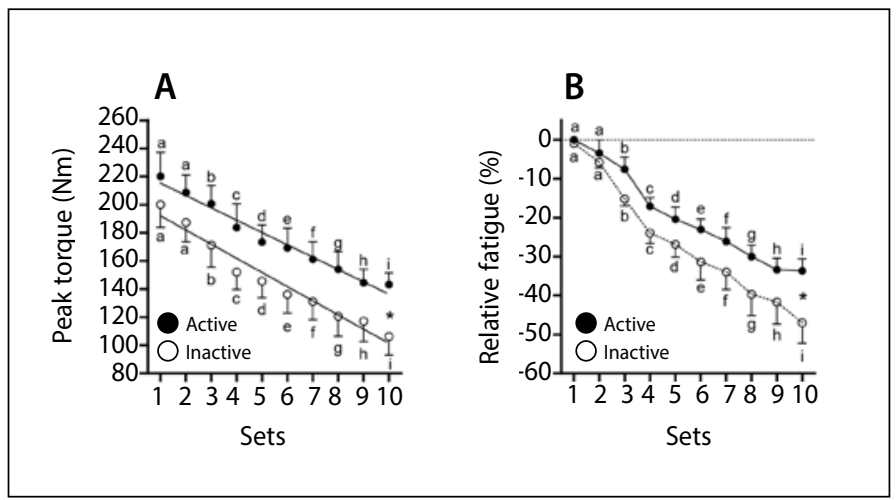

Figure 7. Decline of absolute fatigue (Panel A) and relative fatigue (Panel B) after 10 sets of 10 concentric isokinetic mode knee extensions at $120^{\circ} \mathrm{sec}^{-1}$ of active and inactive subjects. Different letters indicate statistically significant $(p<0.05)$ differences between sets. * statistically significant $(p<0.01)$ differences between groups.

\section{DISCUSSION}

The major findings of the present study were: 1) a reliable peripheral fatigue exercise protocol in healthy adults; 2) active adults were more able to develop muscle strength than inactive subjects; 3) although active subjects develop strength there is no difference between the fatigue responses of dynamic muscle action between groups.

Our data in isometric and dynamic fatigue protocol presented in general association to physical activity level respectively were lower than other studies ${ }^{8-11,23}$ found variations between $50 \%$ to $86 \%$. The differences presented in our study might be explained by the contractile action that is given by the eccentric and concentric actions promoted by skeletal muscle responsible to knee extension, moreover ${ }^{24}$.

Some parameters could be clarifying this large difference between protocols. The first point to address is protocol duration. Studies have indicated variation in time of 210 seconds $^{9}, 270$ seconds $^{8}$ and $390 \mathrm{sec}-$ onds ${ }^{11}$. In our study, the protocol length was 505 seconds corresponding to $28 \%$ over time of ${ }^{11}$ data with highest term realization, additionally this fact could be able to promote a higher metabolic stress. The second point corresponds to the angular velocity used on studies, such as Carregaro et al. ${ }^{9}$ that used the angular velocity of $60^{\circ} \mathrm{s}^{-1}$ and $180^{\circ} \mathrm{s}^{-1}$ with three sets of 10 repetitions and rest of 60 seconds between sets found a peak torque drop by $20.8 \%$ and $13.3 \%$. Astorino et al. ${ }^{8}$ used the angular velocity of $180^{\circ} \mathrm{s}^{-1}$, using two sets of 40 repetitions totaling a total work of 80 repetitions with three minute rest between sets found reduction (35.6\%) similar to our study. Third point, the total volume of work performed could be considered as an important factor to induce muscular fatigue. Rawson ${ }^{23}$ used the angular velocity of $180^{\circ} \mathrm{s}^{-1}$ in 30 repetitions by one minute rest, totalizing 150 repetitions, founded a drop at $45 \%$ of peak torque. Mercer et al. ${ }^{25}$ used the angular velocity of $60^{\circ} \mathrm{s}^{-1}$ with one series with five repetitions fell by $22.3 \%$, showing a decrease in the total volume of working, but with exponentially increased overhead. In this way, it is possible that protocols with higher total work volume are more efficient at this angular speed higher than $120^{\circ} \mathrm{s}^{-1}$, therefore the protocols tend to reach the approximate time of 10 minutes. Metabolically, it is possible to speculate that the time element in these protocols has glycolitic predominance.

To our knowledge, there is only one study ${ }^{15}$ available in the scientific literature that evaluated the influence of physical activity level and neuromuscular fatigue development in healthy individuals. In our study, active individuals presented higher levels of muscle strength in both isometric and dynamic protocols compared to inactive. However, there were no differences in fatigue process between the active (Isometric: $35 \pm 6 \%$; Dynamic: $31 \pm 4 \%$ ) and inactive (Isometric: $-33 \pm 5 \%$; Dynamic: $-46 \pm 5 \%$ ) groups.

Similar results were found in other studies ${ }^{26}$ compared young and old subjects strength and fatigue in muscle, showing that young people produce higher levels of forces in elderly subjects, with no differences on fatigue levels. A possible mechanism for this may be to address central and peripheral muscular activation independently of age and $\operatorname{sex}^{27}$. We believe an explanation of no differences on muscular fatigue found in this study may be related to central and peripheral muscle activation, taking into account differences between activation of muscle fibers, also in the development of muscle fibers and biochemical changes ${ }^{27-29}$.

During isometric exercise with a constant submaximal load, there is a time-dependent increase in electromyographic signal. An increase may be due to increased peak amplitude, the change in motor unit recruitment order or increasing motor neuron firing rates, that could be used as a compensation factor to the loss of motor function. In this way, Paasuke et al..$^{15}$ found no differences on reflex latency patellar during isometric contractions indicating no changes in sensory and motor nerve conduction during submaximal protocol isometric fatigue knee 
extensors in power athletes, strength and untrained subjetcs. Considering the differences present between active and non-active individuals, we can comment on the muscle and neural properties already observed between athletes and non athletes ${ }^{11}$. Thus, it is possible to consider that athletes and active individuals within its particularities, have greater transverse muscular segment ${ }^{16}$, greatest difference in the ratio of type I / I fibers than non-trained individuals and resistance athletes ${ }^{2}$. Similar results were found by Leme et al. ${ }^{30}$, their study observed that in individuals with high aerobic capacity lower strength maintenance in high intensity activities, may be due to typing predominance of muscle fiber.

Regarding the dynamic actions, our data are similar to the study of Blacker et al. ${ }^{31}$ being shown that individuals who performed strength training showed marked decrease in torque percentage (16.5\%), in the eccentric phase, when compared with groups that performed predominantly aerobic exercises (7.2\%) and compared to physically active individuals to presented drop was $6.5 \%$. Leme et al. ${ }^{30}$ presented results showing subjects with different types of training completed the same amount of total work during the sessions of strength training. The authors considered that endurance athletes have greater resistance to fatigue compared to sprinters, wrestlers and weightlifters. This information corroborates to our dynamic muscle strength parameters that showed the same fatigue level but with lower peak force when compared to the inactive group. Additionally, the time protocol could be considered as an important parameter to promote metabolic substrate accumulation or be able to increase acidosis, indicating impairment on muscular performance during a dynamic protocol. It is therefore unclear from the scientific literature, how fitness status or just physical activity levels can influence the kinetics of blood lactate concentrations, or how the peak concentrations that occur during or immediately post exercise could contribute to peripheral acute fatigue.

\section{CONCLUSION}

The present study demonstrated that physically active adults presented higher strength than inactive subjects. Additionally, the fatigue protocol applied in this study is useful to promote acute peripheral muscle fatigue on isometric and dynamic strength in both groups. On the other hand, the fatigue slope was similar in both groups suggesting that neuromuscular responses were affected by the fatigue protocol due to specific metabolic pathways and neurological profile of subjects.

\section{ACKNOWLEDGEMENT}

The authors thank CAPES (Coordenação de Aperfeiçoamento de Pessoal de Nível Superior) fellowships addressed to F. S. Suzuki. The fund providers had no role in decision to publish and preparation of the paper.

All authors have declared there is not any potential conflict of interests concerning this article.

AUTORES' CONTRIBUTIONS: FSS (0000-0002-4745-5788)* and DSB (0000-0003-3993-8277)* were the main contributors to the writing of the manuscript. MMK $(0000-0002-2406-4450)^{*}$ and CASC (0000-0002-3606-0828)* performed the laboratory procedures, as well as recruiting the volunteers, conducting the anthropometric measurements and filling out the questionnaires, and training volunteers in the use of the Isokinetic Dynamometer. The treatment of the signs obtained was done by FP $(0000-0002-7901-3351)^{*}$. AJS (0000- 0002-5407-8183)* and ALE (0000-0002-4941-6475)* evaluated the data from the statistical analysis. FSS, PHM (0000-0002-2016-936X)* and AJFJ (0000-0001-8069-2366)* conducted the literature review. The revision of the manuscript and contributions to the intellectual concept of the study were provided by ACA (0000-0002-9644-5068)*, PHM and AJFJ. The revision of the English text was done by JSB (000-0002-9846-4916)*. ${ }^{*}$ ORCID (Open Researcher and Contributor ID).

\section{REFERENCES}

1. Bigland-Ritchie B, Johansson R, Lippold OC, Smith SW. Changes in motoneurone firing rates during sustained maximal voluntary contractions. J Physiol. 1983;340:335-46.

2. Enoka RM, Duchateau J. Muscle fatigue: what, why and how it influences muscle function.J Physiol. 2008:586(1):11-23.

3. Gandevia SC. Spinal and supraspinal factors in human muscle fatigue. Physiol Rev. 2001;81(4):1725-89.

4. Allen DG, Lännergren J, Westerblad H. Muscle cell function during prolonged activity: cellular mechanisms of fatigue. Exp Physiol. 1995;80(4):497-527.

5. Stackhouse S, Dean J, Lee S. Measurment of central activation failure of the quadriceps femoris in healthy adults. Muscle Nerve. 2000;23:1706-1712.

6. lida N, Kaneko F, Aoki N, Shibata E. The effect of fatigued internal rotator and external rotator muscles of the shoulder on the shoulder position sense. J Electromyogr Kinesiol. 2014;24(1):72-7.

7. Ringheim I, Indahl A, Roeleveld K. Alternating activation is related to fatigue in lumbar muscles during sustained sitting. J Electromyogr Kinesiol. 2014;24(3):380-6.

8. Astorino TA, Terzi MN, Roberson DW, Burnett TR. Effect of two doses of caffeine on muscular function during isokinetic exercise. Med Sci Sports Exerc.2010;42(12):2205-10.

9. Carregaro RL, Gentil P, Brown LE, Pinto RS, Bottaro M. Effects of antagonist pre-load on knee extensor isokinetic muscle performance. J Sports Sci. 2011;29(3):271-8.

10. Dipla K, Tsirini T, Zafeiridis A, Manou V, Dalamitros A, Kellis E, et al. Fatigue resistance during high-intensity intermittent exercise from childhood to adulthood in males and females. Eur J Appl Physiol. 2009;106(5):645-53.

11. Derave W, Ozdemir MS, Harris RC, Pottier A, Reyngoudt H, Koppo K, et al. Beta-Alanine supplementation augments muscle carnosine content and attenuates fatigue during repeated isokinetic contraction bouts in trained sprinters. J Appl Physiol (1985). 2007:103(5):1736-43.

12. Theou O, Gareth JR, Brown LE. Effect of rest interval on strength recovery in young and old women. J Strength Cond Res. 2008;22(6):1876-81.

13. Tiggelen DV, Coorevits P, Witvrouw E. The effects of a neoprene knee sleeve on subjects with a poor versus good joint position sense subjected to an isokinetic fatigue protocol. Clin J Sport Med. 2008;18(3):259-65.

14. Schwendner KI, Mikesky AE, Holt WS Jr, Peacock M, Burr DB. Differences in muscle endurance and recovery between fallers and nonfallers, and between young and older women. J Gerontol A Biol Sci Med Sci. 1997;52(3):M155-60.

15. Pääsuke M, Ereline J, Gapeyeva H. Neuromuscular fatigue during repeated exhaustive submaximal static contractions of knee extensor muscles in endurance-trained, power-trained and untrained men Acta Physiol Scand. 1999;166(4):319-26.

16. Häkkinen K, Pakarinen A, Alen M, Kauhanen H, Komi PV. Neuromuscular and hormonal adaptations in athletes to strength training in two years. J Appl Physiol (1985). 1988;65(6):2406-12.
17. Izquierdo M, Häkkinen K, Gonzalez-Badillo JJ, Ibáñez J, Gorostiaga EM. Effects of long-term training specificity on maximal strength and power of the upper and lower extremities in athletes from different sports. Eur J Appl Physiol. 2002;87(3):264-71.

18. Matsudo SM, Matsudo VR, Araújo T, Andrade D, Andrade E, Oliveira L. Nível de atividade física da população do Estado de São Paulo: análise de acordo com o gênero, idade, nível socioeconômico , distribuição geográfica e de conhecimento. Rev Bras Ciên Mov. 2002;10(4):41-50.

19. González-Gross M, Meléndez A. Sedentarism, active lifestyle and sport: Impact on health and obesity prevention. Nutr Hosp. 2013;28(Suppl 5):89-98.

20. Pinheiro MC, Westphal MF, Akerman M. Equity in health according to reports by the Brazilian National Health Conferences since enactment of the 1988 Federal Constitution. Cad Saude Publica. 2005;21(2):449-58.

21. World Health Organization. Glossary of health promotion terms. Geneva:World Health Organization/Division of Health Promotion, Educations and Communications/Health Education and Health Promotion Unit; 1998

22. Escamilla RF, Fleisig GS, Zheng N, Barrentine SW, Wilk KE, Biomechanics of the knee during closed kinetic chain and open kinetic chainexercises. Med Sci Sports Exerc. 1998;30(4):556-69.

23. Rawson ES. Enhanced fatigue resistence in older adults during repeated sets of intermittent contractions. J Strength Cond Res. 2010;24(1):251-256.

24. Enoka RM, Stuart DG. Neurobiology of muscle fatigue. J Appl Physiol (1985).1992;72(5):1631-48.

25. Mercer TH, Gleeson NP, Wren K. Influence of prolonged intermittent high-intensity exercise on knee flexor strength in male and female soccer players. Eur J Appl Physiol. 2003;89(5):506-8.

26. Klass M, Baudry S, Duchateau J. Voluntary activation during maximal contraction with advancing age: a brief review. Eur J Appl Physiol. 2007:100(5):543-51.

27. Russ DW, Towse TF, Wigmore DM, Lanza IR, Kent-Braun JA. Contrasting influences of age and sex on muscle fatigue. Med Sci Sports Exerc. 2008;40(2):234-41.

28. Ascensão A, Magalhães J, Oliveira J, Duarte J, Soares J. Fisiologia da fadiga muscular. Delimitação conceptual, modelos de estudo e mecanismos de fadiga de origem central e periférica. Rev Portug Ciênc Desp. 2003;3(1):108-23.

29. Olkoski MM, Matheus SC, Alexandre F. Respostas bioquímicas e físicas ao treinamento realizado dentro e fora da água em atletas de futsal. Motriz, Rio Claro. 2013:19(2)432-40.

30. Leme V, Panissa G, Julio UF. Effects of interval time between high-intensity intermittent aerobic exercise on strength performance: analysis in individuals with different training background. J Hum Sport Exerc. 2012;7(4):815-25.

31. Blacker SD, Fallowfield JL, Bilzon JL, Willems ME. Neuromuscular function following prolonged load carriage on level and downhill gradients. Aviat Space Environ Med. 2010;81(8):745-53. 